\title{
Muerte, tiempo, memoria. Los megalitos como memoriales culturales
}

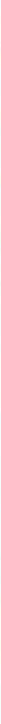




\section{Resumen}

En este trabajo se plantea la significación de los sitios megalíticos como dispositivos culturales dedicados a la fijación material del tiempo. Dado el carácter fundacional que tienen como elemento fundamental de la construcción del paisaje cultural de las primeras sociedades agrarias, los monumentos megalíticos adquieren una extraordinaria capacidad de permanencia en la memoria colectiva, convirtiéndose en referentes materiales de las identidades, las relaciones y prácticas sociales y las ideologías a través de los siglos. Esta capacidad de permanencia excede ampliamente los límites temporales convencionalmente atribuidos a la Prehistoria, entrando de lleno en el ámbito de las sociedades antiguas, medievales y modernas.

\section{Palabras clave}

Ajuares funerarios I Enterramientos I Europa I Ideología I

Lugares de culto I Megalitismo I Monumentos funerarios I Muerte I Paisaje I Patrimonio arqueológico I Religión I Ritos de paso I Simbología
"El culto a los antepasados es el meollo de la fe de los Ashanti. El clan abarca un número inmenso de seres, pero sólo podemos ver una parte de ellos, aquellos que viven en la Tierra. Los otros -la mayoría- no son sino los antepasados, que nos han dejado en parte, pero que, en realidad, siguen participando en nuestra vida. Nos miran, observan nuestro comportamiento. Están por todas partes y lo ven todo. Pueden ayudarnos, pero también castigarnos. Darnos felicidad o condenarnos a la extinción. Deciden sobre todas las cosas. Por eso, el mantener buenas relaciones con los antepasados se vuelve condición sine qua non para garantizar el bienestar de todo el clan y de cada uno de nosotros. Y precisamente el jefe es el responsable de la calidad y la temperatura de esas relaciones. Él es el intermediario y enlace entre las dos inseparables partes del clan: el mundo de los antepasados y el de los vivos. Es él quien comunica a los vivos la voluntad y la decisión de los antepasados ante tal o cual asunto, y también es él quien implora perdón cuando los vivos han violado la tradición o la ley (...) el jefe es el que asigna las parcelas de tierra a las familias. No la puede dar ni vender, porque la tierra es propiedad de los antepasados: ellos están en su interior, en sus entrañas."

Richard Kapuscinski, Ébano.

\section{INTRODUCCIÓN}

Hace miles de años, alguien cogió una piedra ni demasiado grande ni demasiado pequeña (una piedra, digamos, que un ser humano normal pudiera sostener sin romperse la espalda en el esfuerzo), le sacudió un poco el polvo y la colocó en un sitio especial, quizás el sitio donde acababa de dar enterramiento a un ser muy querido, o quizás el sitio donde había tenido una experiencia mística que le dejaría marcado para el resto de su existencia. Posiblemente, ese alguien colocara luego junto a la piedra, o encima de ella, algunos objetos que le resultaban especialmente significativos y se quedase pensativo por unos instantes, contemplando la insignificancia de la vida humana frente al cosmos, la naturaleza y el tiempo. Aunque por razones obvias este acto pueda parecernos tan acusadamente humilde que se antoje excesivo calificar su resultado como "monumento", aquella piedra, a su humilde nivel, transformó para siempre el sitio exacto donde había sido puesta, dotándolo de la enorme fuerza de la voluntad humana de combatir el olvido. Con este minúsculo acto 
anónimo dio comienzo la arquitectura monumental en piedra. Como ha explicado el profesor C. Scarre en el texto que encabeza este volumen, el término "monumento" evoca la intención de preservar la memoria de algo o alguien, haciéndolo notorio y visible en su entorno. Naturalmente, la piedra tiene, frente a otros materiales constructivos, una evidente propiedad de perdurabilidad y resistencia que la hace especialmente adecuada para "monumentalizar" un sitio.

En las sociedades ágrafas, los monumentos tienen mucho que ver con la memoria, y la memoria tiene mucho que ver con los muertos. Dada la importancia de los muertos, en tanto que antepasados, la ideología funeraria ha tenido una enorme importancia en la mayoría de las sociedades prehistóricas. Podríamos definir ideología funeraria como el conjunto de nociones simbólicas que articulan la relación entre los vivos y los muertos (ancestros) a través de prácticas y rituales que, centradas en el tratamiento de los cadáveres (escatología), incorporan una importante dimensión material (GARCÍA SANJUÁN, 2006: 150). La creencia en una vida después de la muerte, la ritualización de las prácticas funerarias, y la utilización de la cultura material (y muy especialmente la arquitectura monumental) para conmemorar a los muertos son elementos prácticamente universales de la conducta humana. En otras palabras, los monumentos son, por su propia definición, la parte más notoria de la plasmación material de la ideología funeraria. La muerte (los antepasados), los monumentos y la memoria convergen en la ideología funeraria de las sociedades prehistóricas: en ausencia del archivo documental escrito que poseen las sociedades históricas, la ideología funeraria supone para las sociedades ágrafas nada menos que la fijación material del tiempo, la memoria, la identidad cultural y, sobre todo, las relaciones sociales y de poder.

Con bastante probabilidad, esa conquista de la historia de la arquitectura a que se ha hecho referencia antes pudo tener lugar dentro de una cueva habitada por una banda de cazadores y recolectores, en el Paleolítico Superior, por lo que no alcanzó mucha difusión en su día (en realidad, en el tiempo en que este figurado suceso tuvo lugar, la humanidad en sí misma no tenía mucha difusión: sus efectivos demográficos eran bastante modestos y se encontraban desperdigados a lo largo y ancho de un planeta dominado por una feroz competencia por la vida en el marco de la cual se afanaban por sobrevivir). Las sociedades cazadoras y recolectoras son bastante "discretas" en la forma que tienen de abordar la fijación material de su memoria: las transformaciones a que los cazadores y recolectores someten a la naturaleza son más bien modestas. La información relativa a las prácticas funerarias de las poblaciones de cazadores y recolectores del Paleolítico Superior europeo no es muy abundante, pero las evidencias disponibles muestran el predominio de inhumaciones individuales en fosas que son a menudo tapadas, rodeados o cubiertas con tierra y pequeñas acumulaciones de bloques de piedra, casi siempre acompaña- das de ajuares consistentes en herramientas, comida y objetos ornamentales. En el Paleolítico Superior europeo los principales lugares sagrados y funerarios fueron cuevas y abrigos poco accesibles y a menudo invisibles a menos que se conociera de antemano su localización, lo cual es congruente con lo que la etnografía nos ha mostrado en relación con las sociedades de cazadores y recolectores, poco o nada dados a alterar físicamente la naturaleza de la que se consideran parte integrante.

Con el comienzo de la forma de vida sedentaria y campesina, en el Neolítico, las ideologías funerarias de las sociedades del Viejo Mundo comenzaron a hacerse más complejas. Aunque la utilización de recónditas cuevas y abrigos como lugares funerarios y santuarios continuó durante mucho tiempo, algo de la discreción y la modestia con que los cazadores y recolectores habían concebido la fijación de su presencia y su memoria en la naturaleza comenzó a perderse. Entre las sociedades móviles de cazadores y recolectores, la memoria está inscrita en la propia naturaleza; en las sociedades de campesinos la naturaleza es transformada y monumentalizada para recibir y fijar a la memoria. Las primeras sociedades agrarias europeas iban a domesticar y a conquistar la naturaleza, y el mensaje resultaría fácilmente reconocible: ese mensaje resultó ser el megalitismo.

\section{TIEMPO. MÁS ALTO, MÁS GRANDE, PARA SIEMPRE}

Con el Neolítico (en la Península Ibérica c. 5600-3200 a.n.e.) arrancó la lucha de los campesinos por domesticar a la naturaleza, por clarear el bosque para abrir campos de cultivo y por proteger al ganado de las alimañas. En esta fase de la historia humana, la invención de los monumentos iba a asumir un importante papel ideológico. Con una creciente seguridad económica (almacenamiento de excedentes, menor vulnerabilidad frente a años malos) y una densidad demográfica todavía bastante baja (lo que les evitaría los conflictos sociales y territoriales que iban a comenzar a darse en periodos posteriores, fundamentalmente a partir de la Edad del Bronce), entre los milenios VI y III cal a.n.e., las sociedades campesinas de amplias regiones europeas dispusieron de las reservas energéticas, el tiempo y la mano de obra suficiente como para dedicar importantes esfuerzos a la erección de soberbios monumentos megalíticos a mayor gloria de los dioses y los antepasados. El megalitismo se constituyó en un complejo y poliédrico fenómeno cultural que fijaba y aseguraba el orden social y natural (SHERRATT, 1990: 334; 1995: 355) mediante un sofisticado arsenal de mecanismos de reproducción ideológica, de entre los cuales uno merece especial atención aquí: la fijación y manipulación del tiempo y la memoria. Si aceptamos la observación de que la sociedad neolítica europea estuvo impregnada por los rituales de culto a los antepasados (BRADLEY, 1998: 66), es difícil no coincidir con la afirmación de Felipe Criado Boado (1989: 85) de que los megalitos se convirtieron en el tiempo mismo, o más exactamente en la encarnación 
3. Ortostato 21 del dolmen de Soto (Trigueros, Huelva). Detalle del motivo antropomórfico representado / Foto: M. A. BLANCo de LA Rubia. Fuente: EMpresa Pública de GESTIÓN DE Programas Culturales

física y medible de un tiempo lineal contrapuesto al tiempo estancado de los cazadores y recolectores.

Distintos tipos de evidencia han venido mostrando los procedimientos por los que tiempo y memoria se materializaban en los megalitos. En primer lugar, los sitios megalíticos capturaban el tiempo en forma de episodios astronómicos que marcaban los ciclos de la vida y la naturaleza. Para las primeras sociedades agrarias, el movimiento cíclico de los cuerpos celestes tenía gran importancia en clave de los procesos biológicos y por supuesto constituían la principal referencia para el cálculo del paso del tiempo (MORLEY, 2007). Esta voluntad de conmemoración del tiempo sobrehumano (tiempo cíclico de la naturaleza, tiempo de los movimientos de los grandes cuerpos celestiales que presiden la vida) quedó materializada en las pautas de orientación astronómica que los monumentos megalíticos muestran y que han sido estudiadas, entre otros, por el profesor M. Hoskin (2001), colaborador en este volumen. Posiblemente en ninguna parte quede mejor expresada la conexión entre megalitismo y astronomía que en el magno monumento de Newgrange (Irlanda), donde un sofisticado diseño arquitectónico permitía que el día del solsticio de invierno, los primeros rayos del sol naciente penetraran hasta el fondo de la cámara, iluminando allí por unos instantes un altar de piedra sobre el que reposaban los huesos de los antepasados (STOUT, 2002).

En segundo lugar, el megalitismo incorporaba el tiempo en forma de los mismos depósitos de restos humanos, verdadero inventario genealógico hecho con los vestigios de las generaciones pretéritas. En numerosas cámaras funerarias se ha comprobado que los cuerpos eran depositados completos y luego, pasado un tiempo, los huesos secos eran reorganizados espacialmente, conformándose un verdadero archivo de restos físicos de personas (THOMAS, 1993: 35). En distintos lugares de Europa se han constatado casos de reliquias y objetos sagrados hechos en hueso humano, como por ejemplo "cráneos-copa", cráneos incisos o trepanados o ídolos sobre hueso largo. Más que lugares de reposo, las cámaras mortuorias megalíticas actuaban como casas de los antepasados, donde se llevaban a cabo a actividades de manipulación y gestión de los vestigios de las generaciones pasadas y por tanto del tiempo genealógico. En el caso del Neolítico italiano, se ha señalado que el enterramiento de gente en las proximidades de los poblados mezclaba de forma efectiva las biografías personales con la "historia" de más larga duración del grupo, proporcionando a todo el medio físico en el que las personas se desenvolvían un sentido de ascendencia y temporalidad (ROBB, 2007: 64).

En tercer lugar, estudios llevados a cabo en los últimos años han profundizado en la significación que determinados elementos "portables" de la cultura material asociada al megalitismo pudieron tener en términos
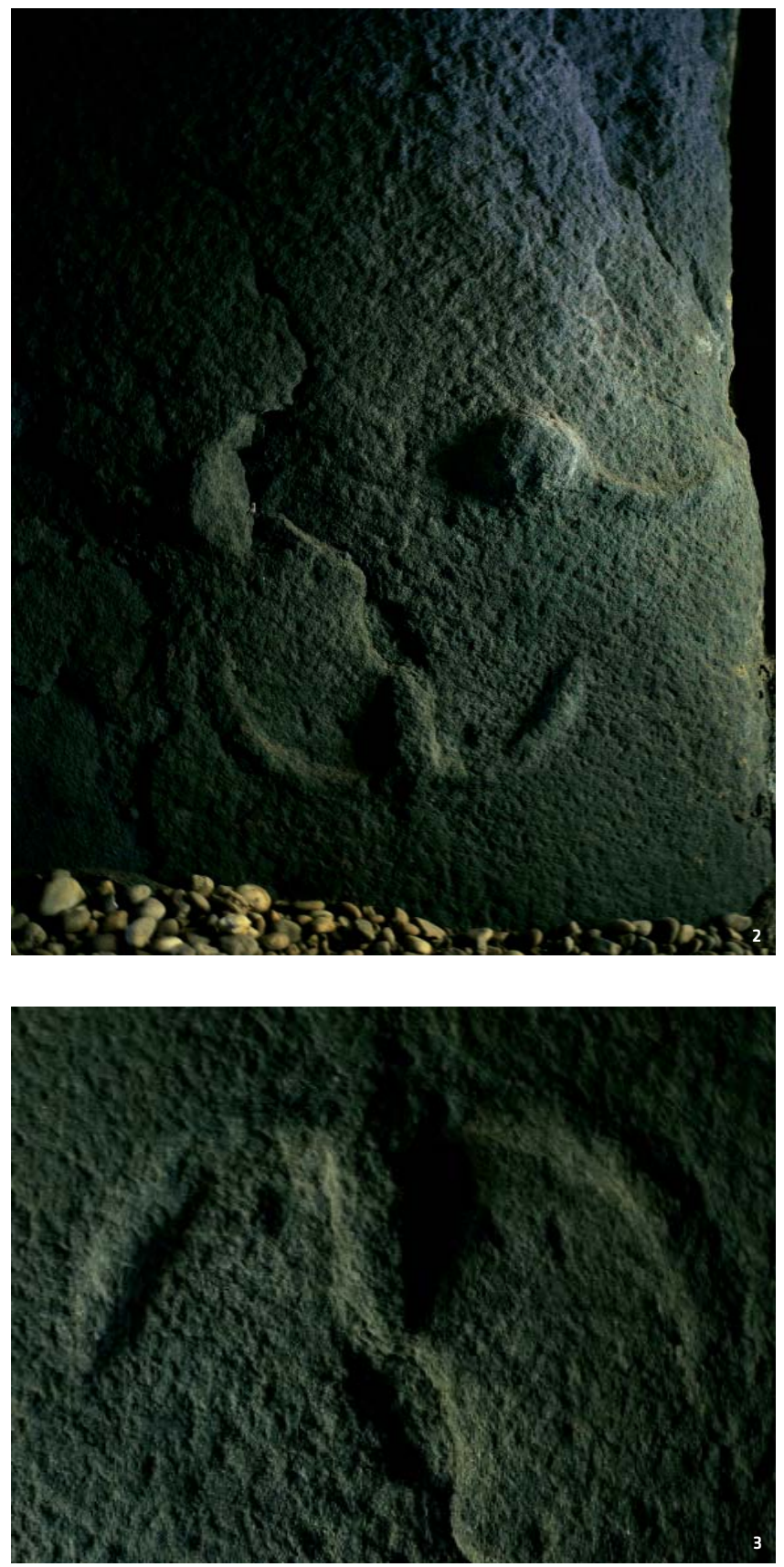

mnemónicos. Así, por ejemplo, los Ilamados ídolos-placa que frecuentemente aparecen como parte de los ajuares funerarios de los megalitos del Neolítico y la Edad del Cobre de la mitad occidental de la Península Ibérica han sido interpretados en términos de marcadores clánicos o registro de los linajes ancestrales (LILLIOS, 1999a; 2003). Igualmente, se ha señalado la utilización entre los ajuares funerarios de objetos hechos 
4. Estructura 5 del tholos del complejo funerario de Palacio III (Almadén de la Plata, Sevilla). Esta estructura fue excavada en la roca madre por debajo del nivel de base de la cámara del tholos, y contenía un fragmento de estela decorada (Estela nº 3) / Foto: LeONARDo GARCía SANJUÁN

5. Dibujo reconstructivo de la Estela $n^{0} 3$ del tholos del complejo funerario de Palacio III (Almadén de la Plata Sevilla) mostrando los restos de pintura identificados/

Dibujo: Primitiva Bueno Ramírez y Rodrigo de Balbín Behrmann
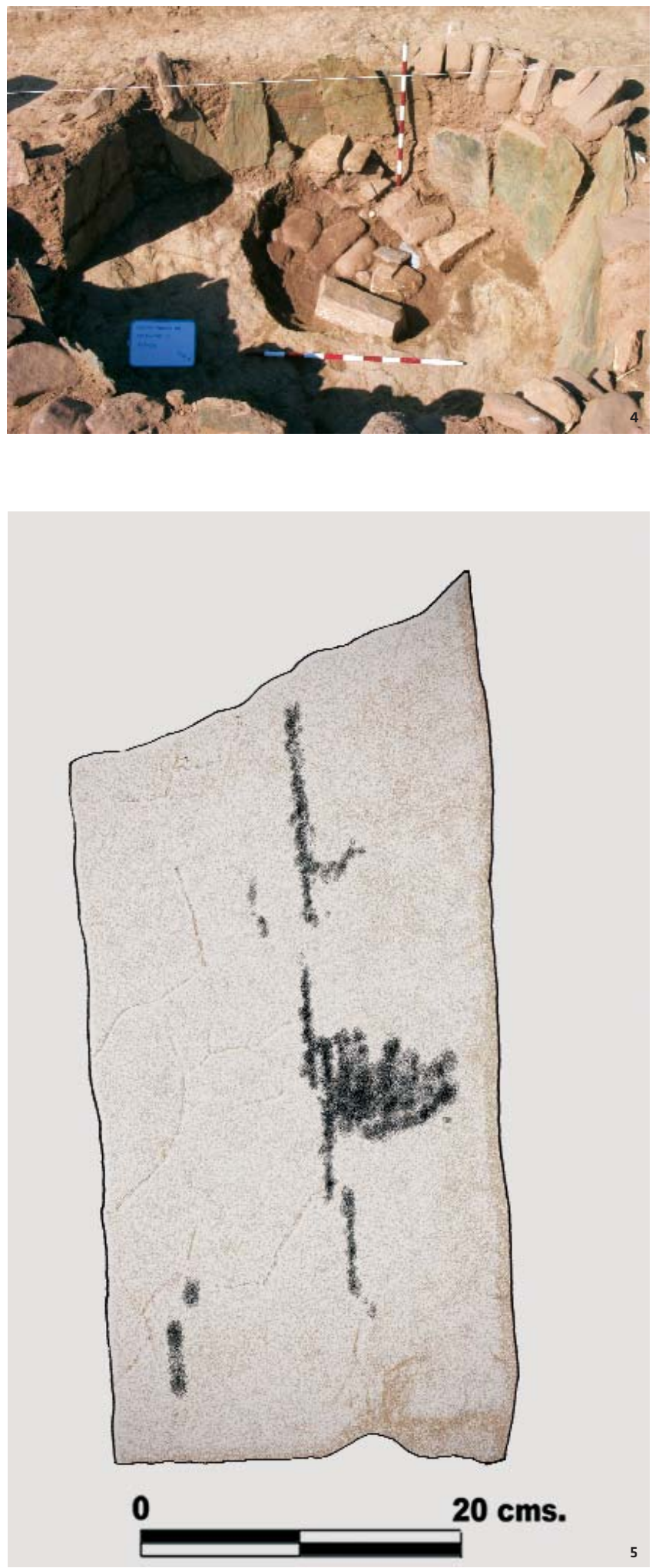

con materias primas exóticas que, por sus especiales características físicas, eran preferidas para dotar de significado a los amuletos y las reliquias que se pasaban de generación en generación. Es por ejemplo el caso de las piedras de moler de anfibolita encontradas en sitios portugueses (LILLIOS, 1999b: 253) o de los amuletos de cuarzo (FORTEZA GONZÁLEZ et al., 2008).

En cuarto lugar, las cámaras megalíticas fijaban el tiempo mediante los complejos programas iconográficos a que daban soporte en forma de escultura y pintura. Por una parte, se ha propuesto que los monolitos que integran los espacios y monumentos megalíticos (menhires, ortostatos, estelas) representaban a menudo antepasados reales o míticos, cuya memoria habitaba y protegía el espacio sagrado: se ha propuesto que las piedras en sí mismas sugerían imágenes antropomórficas a los ojos de los constructores y usuarios de los sitios megalíticos (PARKER-PEARSON Y RAMILISONINA, 1998; (ALADO, 2004). Las investigaciones más recientes sobre el llamado arte megalítico, que en este volumen quedan reflejadas en el trabajo de Bueno Ramírez, Balbín Behrmann y Barroso Bermejo, han puesto de manifiesto la fuerza expresiva que debían tener algunas de estas representaciones, por ejemplo en cuanto a formas, colores y símbolos, evocando a poderosos personajes del pasado. Por otra parte, se han comenzado a identificar numerosos casos de re-utilización de fragmentos de viejas estelas y menhires en la fábrica arquitectónica (paramentos, techumbres) de cámaras de nueva construcción (PATTON, 1993; CASSEN, 2002; BUENO RAMÍREZ et al., 2004; etc.). El cuidado puesto en el transporte, adaptación y re-utilización en cámaras funerarias nuevas de antiguas representaciones que ya habían pasado un tiempo formando parte de otro espacio o monumento sugiere que la significación de los megalitos como focos de permanencia del pasado (mítico o genealógico) es muy dinámica, y que según las formas imperantes de la ideología funeraria, las representaciones cambiaban de lugar y aspecto. Las imágenes 2 y 3 muestran dos ejemplos de esta práctica identificados en el Dolmen de Soto (Trigueros, Huelva), donde en el ortostato 21 se reconocen unos motivos antropomórficos (ojos, cejas, nariz) que sugieren que ese monolito es una estela colocada bocabajo, quizás como resultado de una reutilización que supone la apropiación de una pieza más antigua o procedente de otro monumento (quizás "condenándola"). Las imágenes 4 y 5 muestran un caso posiblemente análogo, correspondiente a la identificación en la base de la cámara del tholos del complejo funerario de Palacio III (Almadén de la Plata, Sevilla) de una subestructura excavada en la roca madre (por debajo del nivel del suelo de la cámara), y dentro de la cual se encontró, cuidadosamente colocado, un trozo de una estela pintada que parece estar también reutilizada.

Este fenómeno tiene de hecho una trascendencia de mayor alcance, ya que, en realidad, lo que se aprecia en numerosos casos es la erección de monumentos megalíticos completamente nuevos encima (o en las proxi- 
midades de) otros anteriores (incluso en conexión arquitectónica, es decir, por ejemplo compartiendo accesos). En la Península Ibérica, se ha constatado que, en la Edad del Cobre (c. 3200-2100 a.n.e.), se construyeron cámaras de tipo tholoi (con techumbre de falsa cúpula) en las proximidades de dólmenes de galería más antiguos. Esta práctica parece representar un complejo equilibrio ideológico entre continuidad y transformación: la construcción de una cámara funeraria completamente nueva supone una cierta noción de ruptura con el pasado, pero al mismo tiempo, su ubicación precisamente junto a (o encima de) una construcción más antigua parece representar la voluntad de mantener el vínculo genealógico que el sitio en sí mismo ya ha adquirido. Estos casos pueden ser interpretados bien como un fenómeno de continuidad (se renueva el espacio de uso tradicional mediante el empleo de conceptos ideológicos y técnicas arquitectónicas nuevas), o bien como un fenómeno de ruptura (una ideología nueva se apropia de un sitio sagrado pre-existente). Los términos ideológicos exactos de lo que esta continuidad en el uso de los mismos sitios monumentalizados puedan representar nos son esencialmente desconocidos, y puede que, por la propia esencia de los datos arqueológicos, nunca los conozcamos en detalle. Pero con toda seguridad podemos valorarlos por analogía con otros fenómenos conocidos en contextos histórico-culturales distintos. Por ejemplo, en clave de la tradición cristiana europea, que pueden resultar más familiar al lector no especialista en Prehistoria, estas prácticas serían análogas bien a la reforma de una iglesia de construcción gótica mediante el añadido de una capilla de estilo barroco (un fenómeno de transformación del espacio dentro de una sustancial continuidad ideológica de fondo) o bien a la construcción de una iglesia encima de un templo romano o de una mezquita musulmana (un caso de dominación y apropiación de un sitio sagrado contemplado como rival).

Finalmente, incluso el propio factor locacional (es decir, la elección del lugar donde se ubican los monumentos ¿por qué un lugar y no otro cualquiera?) puede incorporar un sentido de temporalidad. Según han demostrado distintos estudios, la ubicación de megalitos y monumentos tumulares en las Islas Británicas o Escandinavia (WHEATLEY, 1995; 1996:92; LAGUERAS, 2002) responde en ocasiones al deseo de incorporar dentro del campo de visión (cuenca visual) de un monumento dado otros sitios pre-existentes de especial significación. Distintos ejemplos de este tema son examinados por David Wheatley y Patricia Murrieta Flores en este mismo volumen.

¿Cuál es la razón de que los monumentos megalíticos funcionen, de tantas formas distintas, como dispositivos de gestión del tiempo? Para las sociedades ágrafas, la memoria está escrita en la tradición oral y en la cultura material, especialmente en aquella cultura material que mejor puede resistir la degradación que el tiempo impone. Pero es que además, la producción y gestión del Pasado constituye una poderosa herramienta política. Lo es en la actualidad y lo ha sido en otras épocas, especialmente entre las sociedades altamente jerarquizadas y estatales (es decir, las sociedades donde existe mayor conflicto social). La gestión del tiempo pasado tiene una clara significación en términos de ideología política: el culto a los ancestros (antepasados fundadores, seres míticos primordiales) constituye en las sociedades prehistóricas y antiguas un poderoso elemento de afirmación ideológica. Esa afirmación ideológica puede proporcionar legitimación y refuerzo a la posición de las elites en la competición por el poder inter e intra-clánico (culto a los antepasados como elemento de supremacía o dominación). De forma inversa, la invocación al Pasado y a los antepasados también puede tener gran potencia como mecanismo de autoafirmación y defensa frente a la coerción política y frente a la influencia (o imposición) de valores culturales foráneos (culto a los antepasados como elemento de resistencia).

\section{MEMORIA. SOCIEDADES QUE CAMBIAN, SITIOS QUE PERMANECEN}

De forma general, en Europa, la práctica de construir monumentos megalíticos comenzó a disminuir de intensidad o, según qué regiones, desaparecer, entre finales del III milenio y comienzos del II milenio a.n.e., es decir, con el comienzo de la Edad del Bronce (en la Península Ibérica c. 2100 850 a.n.e.). Esto, sin embargo, no ocurrió de forma regular u homogénea en todas partes: en algunas regiones, la práctica del megalitismo continuó o se reforzó en este periodo, como ocurrió por ejemplo en el Egeo o algunas islas del Mediterráneo occidental, especialmente Córcega, Cerdeña y Baleares. Con las transformaciones sociales y económicas que se dieron en este periodo, muchos de los elementos de la vieja ideología funeraria neolítica que habían posibilitado la aparición del megalitismo se fueron debilitando y pasaron a jugar un papel más secundario. Sin embargo, para entonces, después de casi 3000 años desde que el megalitismo comenzara a convertirse en el mensaje con el que las primeras sociedades neolíticas iban a proclamar su conquista de la naturaleza, la densidad, visibilidad y presencia de los paisajes de las grandes piedras era ya muy fuerte. Los megalitos habían contribuido a transformar la naturaleza para siempre, dando lugar al nacimiento de un paisaje enteramente nuevo. De hecho, quizás lo correcto sea entender que durante el Neolítico tuvo lugar la invención del paisaje: a partir del Neolítico, el medio físico que envolvía la vida humana pasó a tener un creciente aspecto enculturado y monumentalizado, en el que determinados lugares naturales alterados (transformados) y determinadas construcciones más o menos conspicuas dotaban a la naturaleza de poderosos significados ideológicos y matices simbólicos (las consecuencias más biológicas de la transformación neolítica del medio físico, tales como el clareo de bosques para el cultivo, la introducción de especies animales y vegetales nuevas, etc. son mucho más importantes, pero no son objeto de discusión en este trabajo). 
6. Planta del tholos de Las Canteras (El Gandul, Alcalá de Guadaira, Sevilla) y covachas de la Edad del Bronce que reutilizan el túmulo / FUENTE: HURTADO PÉREZ; AMORES CARREDANO, 1984
7. Urna de cremación turdetana (Edad del Hierro) encontrada sobre la cueva artificial (hipogeo) de Cueva Antoniana (Cilena, Sevilla) / Fuente: EscACEnA CARRASCo; BELÉN DEAMOS, 1994: 245

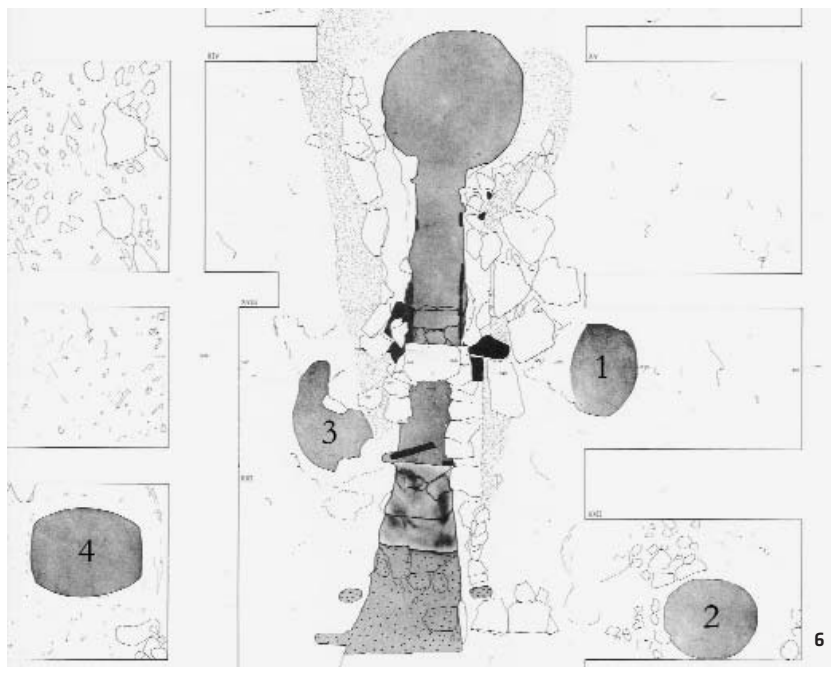

Por tanto, las sociedades europeas de la Edad del Bronce y la subsiguiente Edad del Hierro heredaron de sus predecesoras neolíticas no sólo un legado de sistemas de creencias, sino también una verdadera malla de sitios y paisajes donde esas creencias se materializaban. Aunque estas comunidades quizás no construyeran megalitos, sí fueron conscientes de su existencia y los reverenciaron como venerables focos de lo sagrado y como expresión material de la memoria. La prominencia de los sitios ancestrales podía proceder de su resonancia en las tradiciones orales (arqueológicamente inverificable), o de sus propiedades físicas, como por ejemplo su forma y tamaño, la ubicación (sitios conspicuos o llamativos), visibilidad (prominencia topográfica) o asociaciones simbólicas (todas las cuales pueden ser contrastadas arqueológicamente). Conforme las sociedades europeas de la Edad del Bronce y la Edad del Hierro se transformaban, desarrollando nuevas ideologías funerarias, los milenarios monumentos megalíticos siguieron siendo fuentes de tradición, identidad y poder. Esto es lo que parece desprenderse de la considerable cantidad de casos que muestran que los megalitos fueron visitados o re-utilizados (a menudo físicamente transformados) por gentes que, si bien no parecían compartir exactamente las mismas creencias y prácticas que habían movido a sus constructores originales, sí conocían su existencia, y los respetaban y veneraban hasta el extremo de utilizarlos como lugares de culto y enterramiento.

Los estudios llevados a cabo en este terreno han constatado por toda Europa la frecuente presencia de inhumaciones de la Edad del Bronce y de cremaciones del Bronce Final y de la Edad del Hierro dentro de las cámaras, sobre los túmulos, o en las proximidades de los viejos monumentos megalíticos. Un buen ejemplo de ello se ha documentado en el norte de Alemania, donde se ha estimado que hasta un tercio de los megalitos presentan este tipo de reutilizaciones (HOLTORF, 1998: 28). En regiones

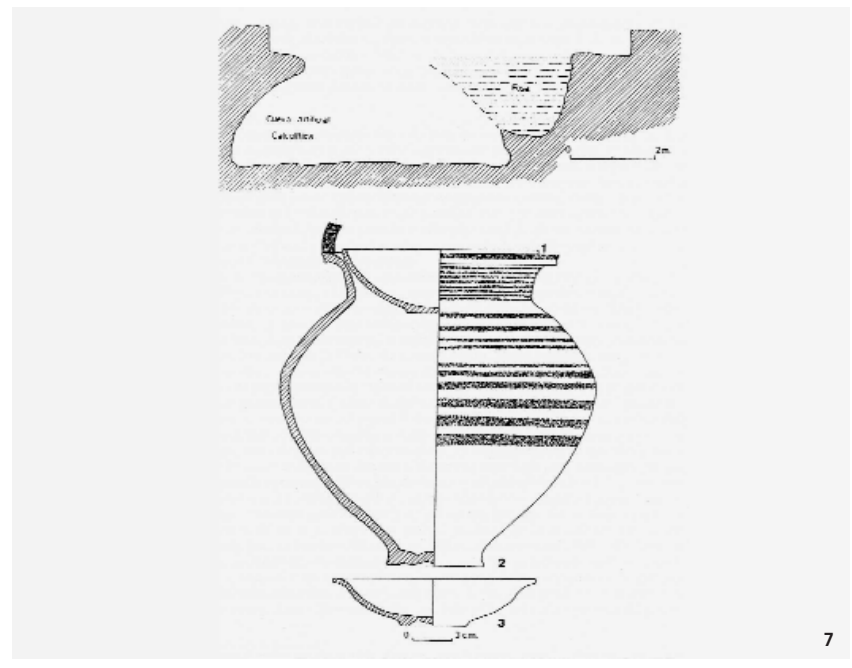

del norte de las Islas Británicas durante la Edad del Bronce se construyeron viviendas a la entrada de antiguos dólmenes, controlando su acceso (HINGLEY, 1996: 236). No parece que la construcción de espacios domésticos a la entrada de antiguas cámaras funerarias sea una coincidencia aleatoria, carente de una significación ideológica.

En la Península Ibérica, estudios recientes han comenzado a indagar en este problema, identificando asimismo una casuística bastante considerable de re-utilizaciones de sitios megalíticos en la Edad del Bronce y en la Edad del Hierro (BEGUIRISTÁIN GÚRPIDE Y VÉLAZ CIAURRIZ, 1999; MONTERO RUIZ Y LORRIO ALVARADO, 2004; GARCÍA SANJUÁN, 2005a; 2005b). Las imágenes 6 y 7 muestran dos ejemplos de estas prácticas tomados del sur de España. En el primero de ellos (imagen 6), el túmulo del tholos de la Edad del Cobre de Las Canteras (El Gandul, Alcalá de Guadaira, Sevilla) fue reutilizado en la Edad del Bronce, abriéndose cuatro covachas dentro de las cuales se practicaron inhumaciones. En el segundo ejemplo (imagen 7), la cueva artificial (hipogeo) Antoniana (Gilena, Sevilla), también de la Edad del Cobre, fue re-utilizada en la Edad del Hierro, colocándose sobre su bóveda una urna funeraria con una cremación.

Cuando a finales del siglo III a.n.e., Roma comenzó el gradual proceso de conquista de Europa occidental, la milenaria (y cada vez más complicada) malla de sitios y paisajes sagrados que había evolucionado en el Neolítico vinculando a las poblaciones locales con su propio Pasado se complicó aún más. El dominio militar y económico romano fue imponiendo gradualmente una serie de elementos de uniformización cultural (integración de regiones en un sistema económico único, legislación, utilización de una lengua común, adhesión al culto imperial, etc.) pero eso no supuso que las poblaciones locales de Hispania, Galia o Britania 
9. Amuleto-aplique fálico doble del depósito ritual romano del sepulcro 14 de la necrópolis megalítica de Las Peñas de los Gitanos en Montefrío (Granada) / Fuente: FerRer PaLmA; ROdRÍGUEZ OLIVA, 1978: FIGURA 4

10. Joya y monedas de época romana depositadas como ofrenda a la entrada del monumento megalítico de Newgrange (Irlanda) / FUENTE: STOUT, 2002: 72

abandonaran de la noche a la mañana sus tradiciones, costumbres y creencias. De hecho, estudios arqueológicos recientes centrados en el noroeste de Europa han reunido información sobre los casos (se cuentan por cientos) en que las necrópolis de época romana se articularon alrededor de viejos monumentos funerarios prehistóricos (EVANS, 1985; WILLIAMS, 1998; BRADLEY, 2002; HOLTORF, 1998). En el caso de la Península Ibérica, una serie de casos semejantes han comenzado a ser examinados con mayor interés (MONTERO RUIZ Y LORRIO ALVARADO, 2004; GARCÍA SANJUÁN et al., 2007).

La idea de que entre los siglos II a.n.e. y V d.n.e. las poblaciones iberorromanas o galorromanas practicaran enterramientos dentro de monumentos megalíticos que para entonces tenían ya varios miles de años de antigüedad puede resultar en principio contraria a la sabiduría establecida. La conquista y colonización romana de Europa occidental ha sido a menudo presentada como un proceso inherentemente positivo para las poblaciones conquistadas, que se habrían visto, sobre todo, beneficiadas por la superioridad tecnológica y cultural de la civilización romana. Sin embargo, esta perspectiva no tiene en cuenta la desesperada resistencia que numerosos pueblos opusieron a la imposición del dominio de Roma: desde el punto de vista de los pueblos sometidos, Roma era una potencia extranjera que imponía su dominio militar y económico con despiadada violencia. Una vez confirmada la irreversibilidad de la derrota, una respuesta ideológica obvia para estas poblaciones pudo ser la invocación de su memoria cultural como medio de resistencia simbólica. Naturalmente, ello habría implicado la adherencia a sitios y monumentos cargados con la fuerza de una memoria ancestral que reafirmaba la identidad que acaba de quedar sometida al poder extranjero. La casuística a este respecto es grande, y se pueden citar muchos ejemplos. En el sitio de Westhampnett (Sussex, Reino Unido) en torno a unos enterramientos de la Edad del Hierro se formaron necrópolis romanas y altomedievales, incluyendo un templete romano dedicado al culto a los antepasados (BRADLEY, 2002:138-139). Igualmente, en el Norte de Francia y Alemania se han registrado cuantiosos enterramientos de época romana dentro de (O en torno a) las estructuras tumulares prehistóricas (BRADLEY, 2002: 118; HOLTORF, 1998: 28-29). Las imágenes 8, 9 y 10 muestran ejemplos de depósitos votivos de época romana encontrados a la entrada de sendas construcciones megalíticas de España e Irlanda.

Paradójicamente, la medida de la importancia ideológica que el uso de monumentos megalíticos antiguos pudo tener dentro del Imperio Romano nos la da un tipo de utilización exactamente opuesto al que cabría explicar como parte de un fenómeno de resistencia. En un análisis de los cultos funerarios de época helenística y romana en el ámbito egeo, que permitió identificar claras evidencias de cultos heroicos y funerarios dentro de numerosos megalitos, se constató la conversión del Tesoro de Mynias (Orcómenos, Beocia, Grecia), un tholos de la Edad del Bronce, en
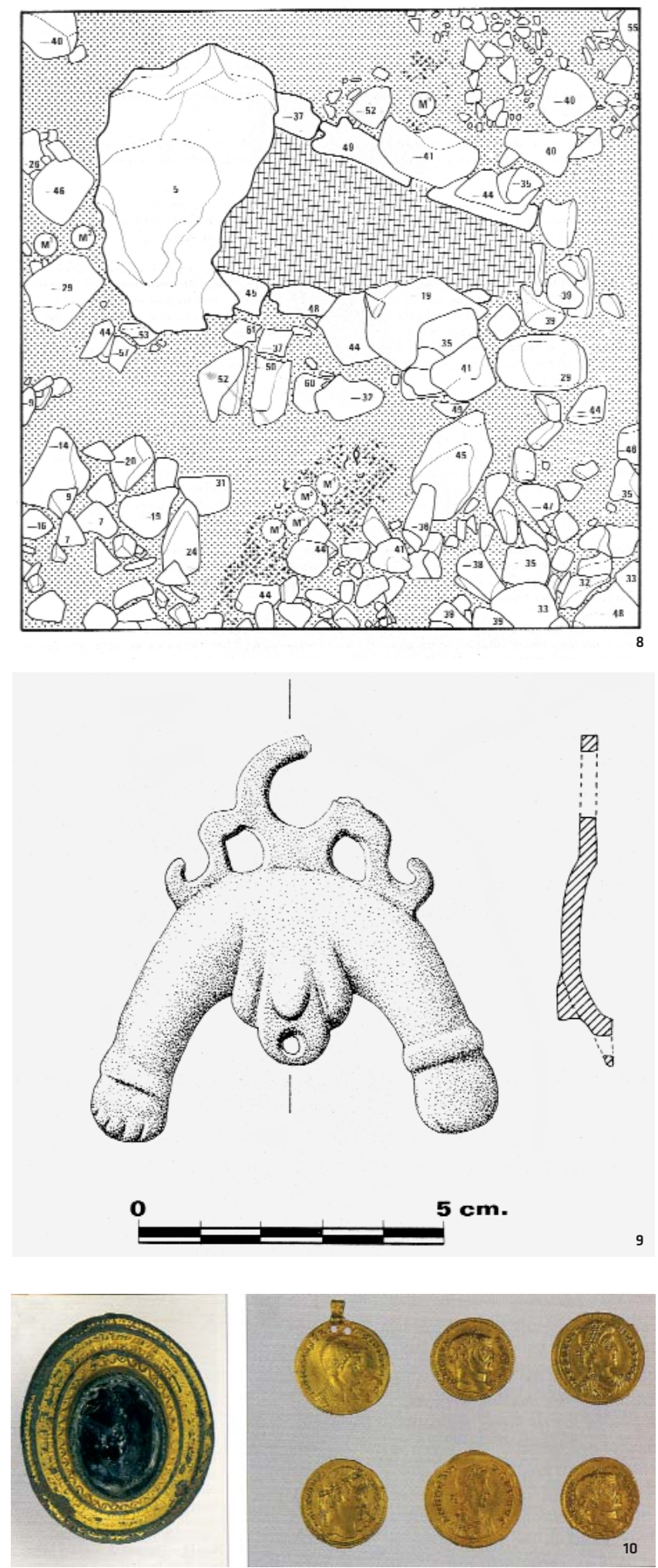

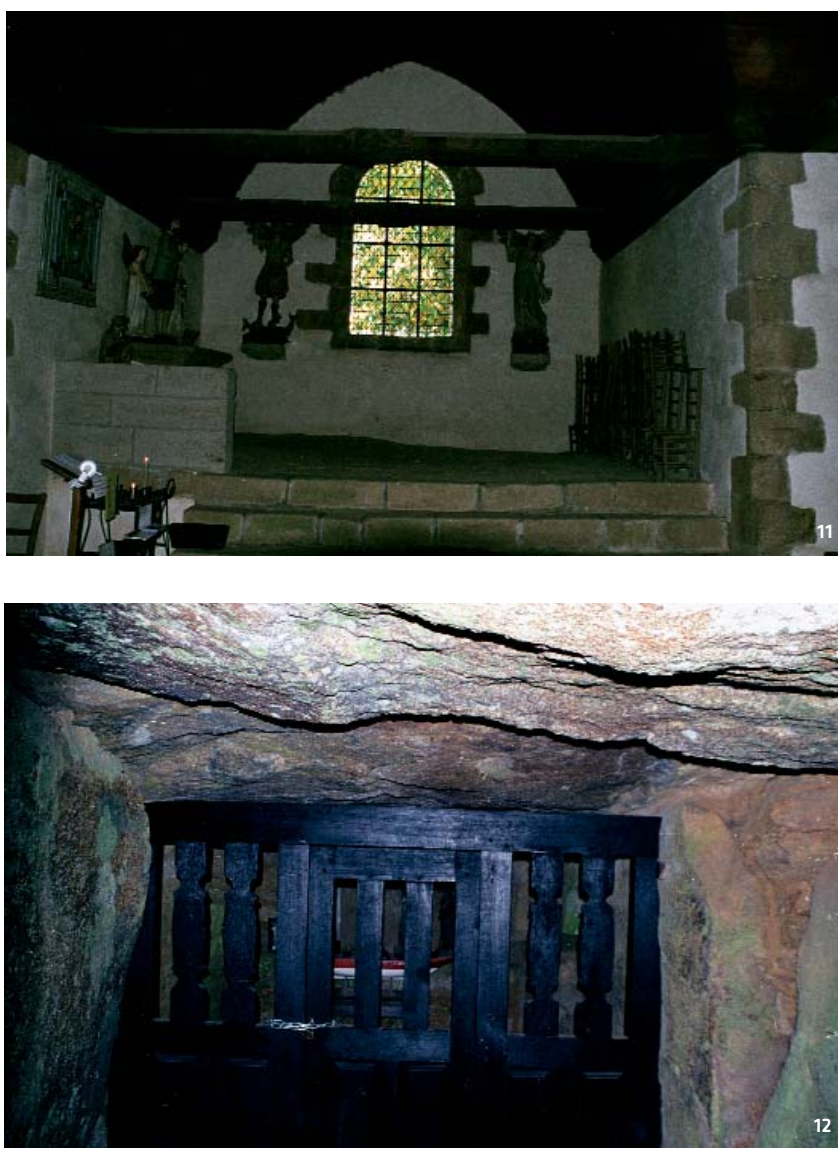

un templo de culto imperial romano (ALCOCK, 1991). Dado que el culto imperial era un mecanismo de control ideológico del estado romano (estaba esencialmente dirigido al reconocimiento del poder absoluto del emperador por parte de las comunidades provinciales), el caso de la cámara megalítica de Mynias constituye una singular manifestación de cómo el poder romano utilizó las tradiciones funerarias locales como una forma de legitimación y promoción política

El uso funerario en época romana de viejos monumentos prehistóricos sugiere la existencia de una fuerte identificación de las sociedades europeas de la Edad del Hierro con los sitios de los antepasados más remotos así como la significación de esos sitios (y la memoria que les era inherente) como herramienta política e ideológica. Esta identificación es de hecho tan fuerte que se proyecta hacia los periodos medieval y moderno de la Historia de Europa. Así, recientemente se ha comenzado a prestar atención a la casuística de cristianización de monumentos prehistóricos, especialmente megalitos. En países como Francia o Reino Unido esta casuística incluye la incorporación de megalitos en la arquitectura de iglesias o la construcción de capillas encima de megalitos en época medieval e incluso moderna (HOLTORF, 1997). En el Alentejo portugués (una de las regiones del continente europeo con mayor densidad de monumentos megalíticos) se han publicado una veintena de casos (a este número habría que añadir otros que no han sido publicados) de antas neolíticas (dólmenes) transformadas en capillas cristianas (las llamadas antas-capelas), o junto a los cuales se construyen capillas cristianas, entre los siglos XVI y XVIII d.n.e. (OLIVEIRA et al., 1997: 55). En el caso de España, el análisis de documentación histórica medieval y moderna relativa a los monumentos megalíticos gallegos (MARTINÓN-TORRES Y RODRÍGUEZ CASAL, 2000; MARTINÓN TORRES, 2001) ha mostrado cómo, a la altura del siglo XVII d.n.e., ciertas romerías y celebraciones tenían lugar en mámoas (túmulos) famosas (MARTINÓN-TORRES, 2001: 112-113).

La imagen 1 muestra el caso del anta-capela de Sao Brisos (Évora, Portugal), mientras que en las imágenes 11 y 12 se ilustra el caso de la iglesia de La Chapelle de Sept-Saints (Cotes-d'Armor, Bretaña, Francia), construida en 1702 d.n.e. y en cuya arquitectura se integró un dolmen neolítico como cripta-capilla. Las imágenes 13 y 14 ofrecen otro ejemplo de este tipo de casos, concretamente la reutilización de dos estatuas-menhires de la Edad del Bronce en los muros laterales de la nave principal de la Catedral de Sant'Appiano (siglo XII d.n.e.) de Sagone (Córcega, Francia). Estas dos estatuas-menhires fueron situadas en un sitio visible y preferente de los muros laterales, haciendo esquina y flanqueando el ábside.

La valoración de estos casos de cristianización de monumentos megalíticos en el medievo tardío o incluso en época moderna plantea un reto al análisis arqueológico e histórico. Una cuestión inevitable es ciertamente la del papel que los sitios sagrados de origen prehistórico juegan en el proceso de cristianización: ¿por qué en las zonas más rurales y aisladas del oeste ibérico se convirtieron en capillas cristianas, en los siglos XVII y XVIII d.n.e., dólmenes de más de 4000 años de antigüedad? ¿Se trató de una cristianización tardía, lo cual implicaría que a esa altura tales sitios eran foco de cultos y creencias no-cristianas, o se trató simplemente de la formalización arquitectónica de una cristianización más antigua en la que lo único que cabe destacar es la (en cualquier caso formidable) continuidad de una serie de sitios como lugares de culto? ¿Eran sólo los sitios ancestrales, como marco físico o espacial, los que mostraban semejante capacidad de permanencia ideológica, o eran también las ideas ancestrales vinculadas a tales sitios las que continuaban activas? Naturalmente, a la vista de la continuidad que manifiesta el uso de ciertos monumentos megalíticos parece legítimo plantearse nuevas preguntas respecto a qué significó la cristianización de Europa y cuándo se produjo en según qué regiones, especialmente las más rurales y aisladas. Como ya hemos discutido en otro trabajo, en la Península Ibérica, distintos edictos eclesiales emitidos entre los siglos IV y VII d.n.e. insistían en la prohibición de prácticas consideradas paganas o heréticas como el culto a los muertos (GARCÍA SANJUÁN et al., 2007). Hasta qué punto el 
13. Estatua-menhir de la Edad del Bronce reutilizada en la Catedral de Sant'Appiano (siglo XII d.n.e.) de Sagone (Córcega).Perspectiva general / Foto: LEONARDo GARCíA SANJUÁN

14. Estatua-menhir de la Edad del Bronce reutilizada en la Catedral de Sant'Appiano (siglo XII d.n.e.) de Sagone (Córcega). Detalle/ Foto: Leonardo García SANJuÁN

milenario culto a los antepasados, arraigado entre las sociedades europeas desde el Neolítico, terminó a merced a lo dispuesto por edictos y cánones oficiales eclesiásticos puede ser otra cuestión. En Escandinavia, entre los siglos IX-XI d.n.e. las comunidades vikingas comenzaron a reutilizar de forma consciente los viejos túmulos funerarios de la Edad del Bronce como acto de resistencia frente a la presión cristianizadora a que eran sometidas y como reafirmación de sus creencias ancestrales (KRISTIANSEN, 2007: 67). En tanto que religión de poder, el cristianismo ha dispuesto históricamente de una burocracia escrita y de una jerarquía bien estructurada. Por otro lado, parece innecesario insistir en que la pervivencia de ideologías religiosas ancestrales ha sido históricamente más importante en las zonas más rurales y periféricas, alejadas del poder del estado, entre cuyas poblaciones, totalmente ágrafas, la utilización de sitios tradicionales, la cultura material y la tradición oral eran los únicos vehículos de fijación de la memoria.

\section{MEMORIALES}

La investigación arqueológica ha comenzado a entender recientemente la significación y alcance de la dimensión tiempo en los monumentos megalíticos. Numerosos elementos presentes en el diseño y ejecución de estas construcciones pueden ser explicados por la voluntad de sus constructores de cuidar y gestionar su Pasado: las sociedades ágrafas utilizan la cultura material como archivo físico de su memoria y de su identidad. Por otra parte, durante bastante tiempo, la arqueología prehistórica concibió los monumentos megalíticos como sitios construidos y usados por las sociedades neolíticas: los megalitos eran entendidos por los especialistas como un fenómeno cultural circunscrito a un tiempo y una sociedad. Los vestigios materiales que aparecían espacialmente asociados a los megalitos (en su interior, en sus accesos) pero que no se correspondían con ese tiempo y esa sociedad eran considerados epistemológicamente irrelevantes e ignorados en tanto que producto de "saqueos", "intrusiones", "violaciones" y "alteraciones". En los últimos dos decenios se ha empezado a comprobar que ese planteamiento era erróneo.

La potente impronta que el megalitismo conforma sobre el medio físico, dando lugar al nacimiento del paisaje (naturaleza manipulada para transmitir una información parcialmente codificada) perdura a través de los siglos de una forma insospechada; como fenómeno paisajístico fundacional, el megalitismo acumula un fuerte ascendiente entre las sociedades europeas a partir del Neolítico. Como se ha visto en las páginas precedentes, incluso en los milenios I y || d.n.e., en época medieval y moderna, se constata en Europa la reutilización y vigencia de sitios y construcciones ancestrales. Quizás el más asombroso ejemplo de la perdurabilidad de los sitios y paisajes sagrados neolíticos como focos de lo ancestral, la memoria, la identidad y el poder político, sea
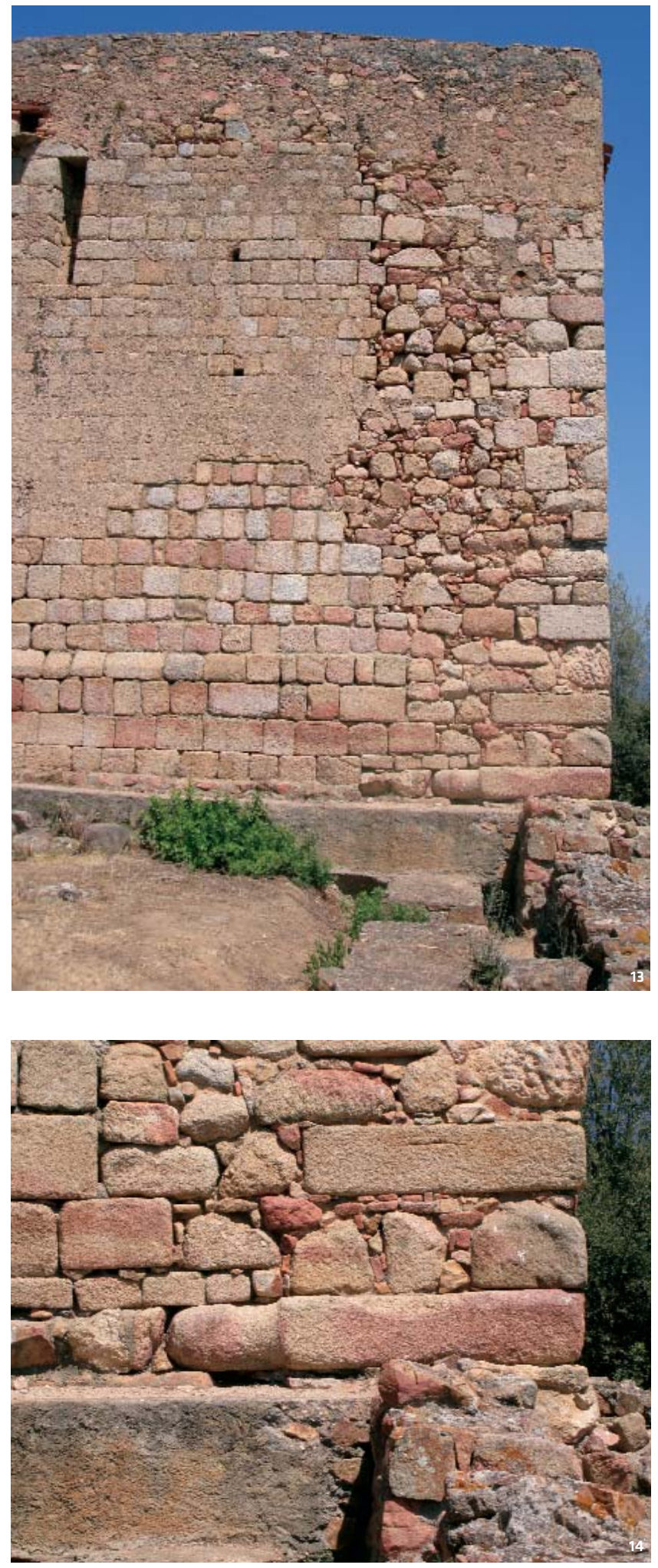
15. Colina de Tara (Condado de Meath, Irlanda). Aspecto general de las construcciones de tipo henge neolíticas / Foto: LUIS MARTínez MonTIEL

16. Colina de Tara (Condado de Meath, Irlanda). Câmara megalítica Mound of the Hostages / Foto: LUIS MARTínez MONTIEL
17. Colina de Tara (Condado de Meath, Irlanda). Estatua de San Patricio / Foto: LuIS MARTÍNEZ MONTIEL
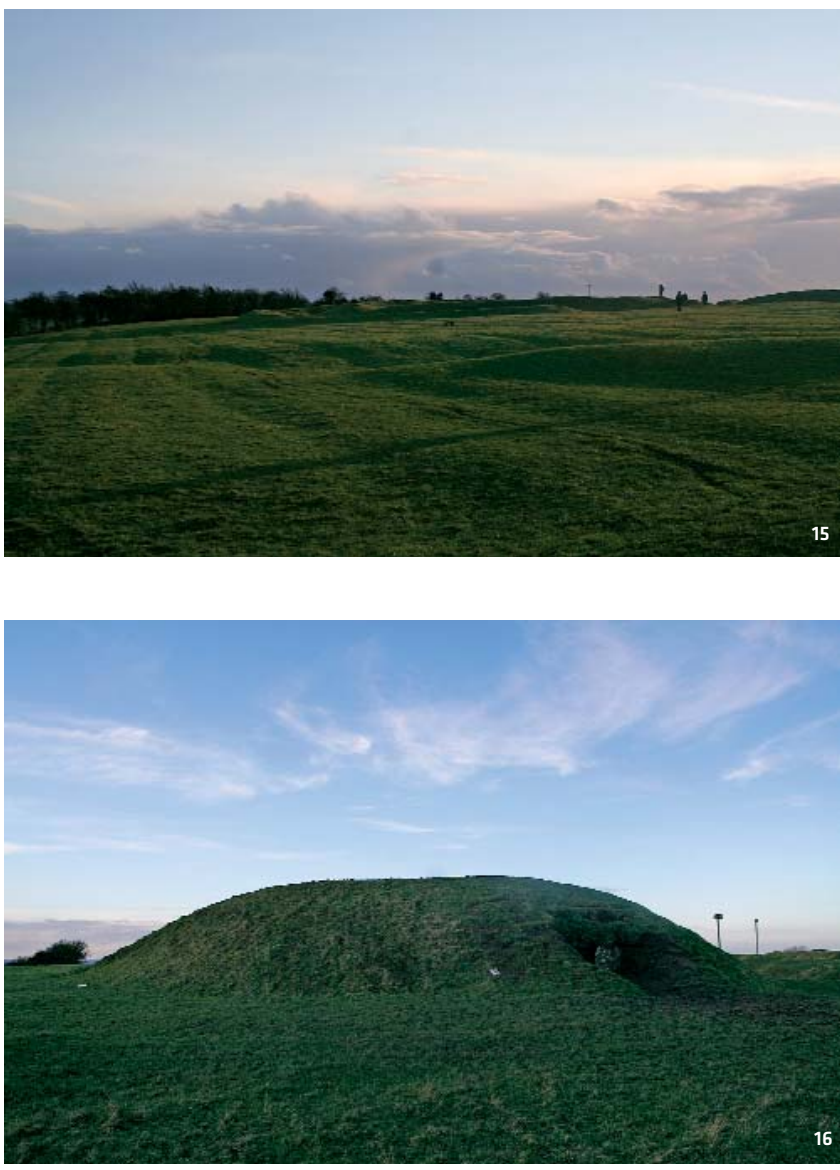

la Colina de Tara (Condado de Meath, Irlanda) (imágenes 15, 16 y 17) Allí se construyeron durante el Neolítico una serie de estructuras de zanja y terraplén (designadas en la literatura anglosajona como henges) y una gran cámara funeraria megalítica conocida como Mound of the Hostages que revelan la función que el sitio tuvo como lugar de reuniones, funerales y conmemoraciones. Durante la Edad del Bronce Final, el Mound of the Hostages fue repetidamente utilizado para depositar urnas funerarias conteniendo restos de decenas de cremaciones (O'SULLIVAN, 2005). Igualmente, el sitio tuvo una fuerte significación política durante toda la Edad del Hierro, siendo considerado, en razón del prestigio que le confería su antigüedad, el lugar de elección y coronación de los jefes y reyes locales. En épocas históricas más recientes, y después de que el sitio fuera cristianizado (mediante la erección de una iglesia), Tara continuó teniendo una significación política tan fuerte que en 1843, el patriota irlandés Daniel O'Connell convocó allí uno de sus "monster meetings" por la independencia de Irlanda, al que asistieron decenas de miles de personas.

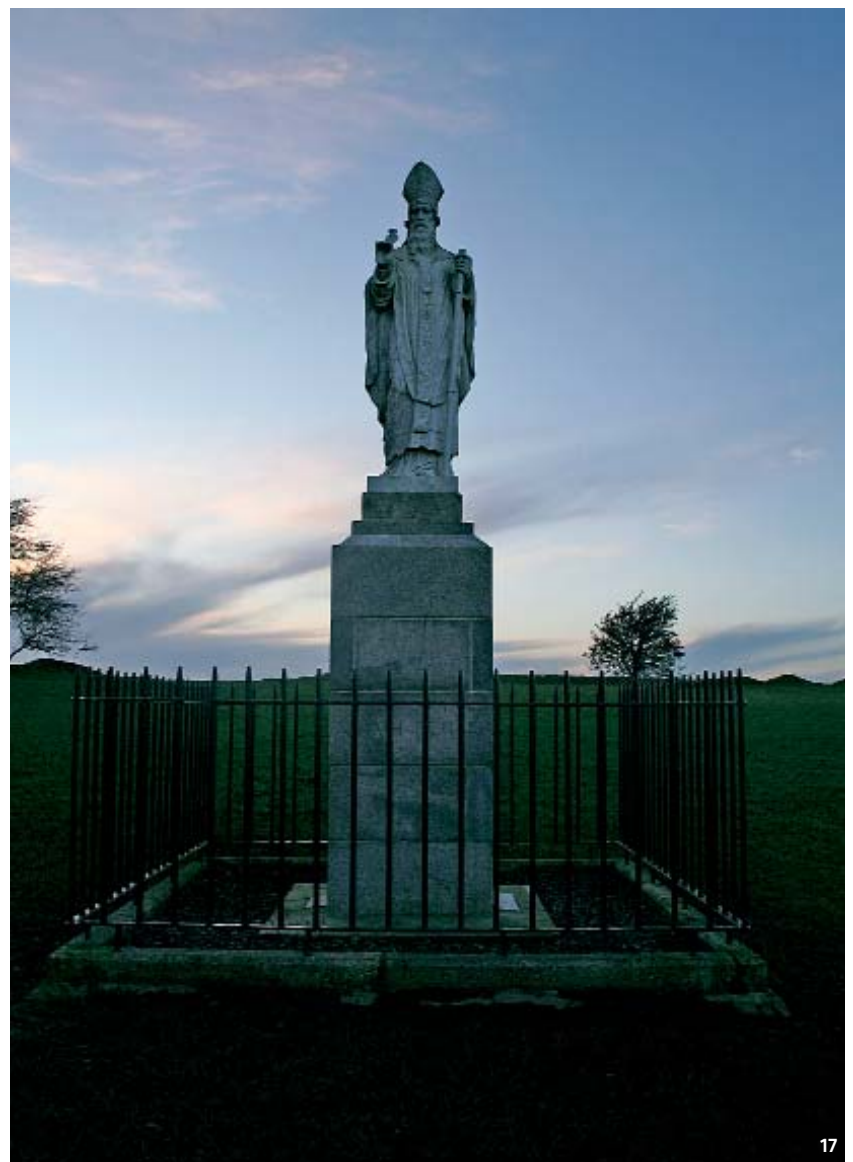

De la discusión planteada en este trabajo se desprende que el megalitismo no es un fenómeno humano que se pueda investigar en base a un marco temporal de referencia circunscrito al periodo Neolítico (y, en el caso de algunas regiones a la Edad del Cobre), ni siquiera a la Prehistoria Reciente, dada la permanencia que muestra como elemento de la memoria y las ideologías religiosas y políticas. Se ha propuesto que el viaje en el tiempo de los megalitos puede ser descrito como "biografías" provistas de una infancia y juventud (construcción y uso original), vida adulta (reutilización por parte de comunidades no constructoras de megalitos) y vida anciana (abandono, desuso e inserción en el folklore y la mitología locales) (HOLTORF, 1998: 35). En todo caso, la conceptualización de los megalitos como simples "sepulcros" o "enterramientos" de cronología prehistórica no hace justicia a la compleja superposición de fases, construcciones, usos, re-utilizaciones y asociaciones contextuales y paisajísticas que muchos de ellos presentan como lugares de control y manipulación del tiempo, el Pasado y los antepasados, lugares de profunda significación ideológica, religiosa y política para sociedades que, generación tras generación, tenían en ellos un referente cultural: verdaderos memoriales culturales. 


\section{Bibliografía}

ALCOCK, S. E. (1991) Tomb cult and the post-classical polis. American Journal of Archaeology, 95, 1991, pp. 447-467

BRADLEY, R. (1998) The Significance of Monuments. On the Shaping of Human Experience in Neolithic and Bronze Age Europe. London: Routledge, 1998

BRADLEY, R. (2002) The Past in Prehistoric Societies. London: Routledge, 2002

BEGUIRISTÁN GÚRPIDE, M. A.; VÉLAZ CIAURRIZ, D. (1999) Megalitos, paisaje y memoria. Un estado de la cuestión. Memoria y Civilización, 2, 1999, pp. 317-327

BUENO RAMÍREZ, P.; DE BALBÍN BEHRMANN, R.; GONZÁLEZ CORDERO, A. (2004) El arte megalítico como evidencia de culto a los antepasados. A propósito del dolmen de La Coraja (Cáceres). Cuadernos de Prehistoria y Arqueología de Castellón, 22, 2004, pp. 47-71

CALADO, M. (2004) Menires do Alentejo Central. Génese e Evolução da Paisagem Megalítica Regional. [literatura gris] Tesis Doctoral. Universidade de Lisboa

CASSEN, S. (2002) Stelae reused in the passage graves of western France: history of research and a sexualization of the carvings En Ritchie, A. (ed.) Neolithic Orkney in its European Context. Cambridge: Oxbow, 2002, pp. 233-246

CRIADO BOADO, F. (1989) Megalitos, espacio, pensamiento. Trabajos de Prehistoria, 46, 1989, pp. 75-98

ESCACENA CARRASCO, J. L.; BELÉN DEAMOS, M. (1994) Sobre las necrópolis turdetanas. En Saéz Fernández, P; Ordóñez Agulla, S. (ed.) Homenaje al Profesor Presedo. Sevilla: Universidad, 1994 pp. 237-265

EVANS, C. (1985) Tradition and the cultural landscape: an archaeology of place. Archaeological Review from Cambridge, 4 (1), 1985 pp. $80-94$

FERRER PALMA, J. E.; RODRÍGUEZ OLIVA, P. (1978) Hallazgos monetarios en las Peñas de los Gitanos (Montefrío, Granada). Cuadernos de Prehistoria de la Universidad de Granada, 3, 1978, pp. 327-342

FORTEZA GONZÁLEZ, M.; GARCÍA SANJUÁN, L.; HERNÁNDEZ ARNEDO, M. J.; SALGUERO PALMA, J.; WHEATLEY, D. (2008) El cuarzo como material votivo y arquitectónico en el complejo funerario megalítico de Palacio III (Almadén de la Plata, Sevilla): análisis contextual y mineralógico. Trabajos de Prehistoria, 65 (2), 2008

GARCíA SANJUÁN, L. (2005a) Las piedras de la memoria. La permanencia del megalitismo en el Suroeste de la Península Ibérica durante el II y I milenios ANE. Trabajos de Prehistoria, 62 (1), 2005 pp. 85-109

GARCÍA SANJUÁN, L. (2005b) Grandes piedras viejas, memoria y pasado. Reutilizaciones del Dolmen de Palacio III (Almadén de la Plata, Sevilla) durante la Edad del Hierro. En Celestino Pérez, S; jiménez Ávila, J. (ed.) El Periodo Orientalizante. Actas del III Simposio Internacional de Arqueología de Mérida. Protohistoria de Mediterráneo Occidental (Mérida, 5-8 de Mayo de 2003). Anejos de Archivo Español de Arqueología, 35. Mérida: CSIC, 2005, pp. 95 604
GARCÍA SANJUÁN, L. (2006) Funerary ideology and social inequality in the Late Prehistory of the Iberian South-West (c. 3300-850 cal BC). En Díaz del Río, P:; García Sanjuán, L. (ed.) Social Inequality in Iberian Late Prehistory. Oxford: Archaeopress, 2006, pp. 149170 (British Archaeological Reports International Series S1525)

GARCÍA SANJUÁN, L.; GARRIDO GONZÁLEZ, P.; LOZANO GÓMEZ, F. (2007) Las piedras de la memoria (II). El uso en época romana de espacios y monumentos sagrados prehistóricos del Sur de la Península Ibérica. Complutum, 18, 2007, pp. 109-130

HINGLEY, R. (1996) Ancestors and identity in the later prehistory of Atlantic Scotland: the reuse and invention of Neolithic monuments and material culture. En Bradley, R. (ed.) (1996) Sacred Geography. World Archaeology 28 (2). London: Routledge، 1996, pp. 231-243

HOLTORF, C. J. (1997) Christian landscapes of pagan monuments. A radical constructivist perspective. En Nash, G. (ed.) Semiotics of Landscape: Archaeology of Mind (Papers presented at a session of 1994 TAG).. Oxford: Archaeopress, 1997, pp. 80-88 (British Archaeological Reports S661)

HOLTORF, C. J. (1998) The life-histories of megaliths in Mecklenburg-Vorpommern (Germany). En Bradley, R.; Williams, H. (ed.) The Past in the Past. The Reuse of Ancient Monuments. World Archaeology, 30 (1). London: Routledge, pp. 23-39

HOSKIN, M. (2001) Tombs, Temples and their Orientation. A New Perspective on Mediterranean Prehistory. Oxford: Ocarina Books, 200

HURTADO PÉREZ, V.; AMORES CARREDANO, F. (1984) El tholos de Las Canteras y los enterramientos del Bronce en la necrópolis de El Gandul (Alcalá de Guadaira, Sevilla). Cuadernos de Prehistoria de la Universidad de Granada, 9, 1984, pp. 147-174

KRISTIANSEN, K. (2007) The rules of the game. Decentralised complexity and power structures. En Kohring, S.; Wynne-Jones, S. (ed.) Socialising Complexity. Approaches to Power and Interaction in the Archaeological Record. Cambridge: Oxbow, 2007, pp. 60-75

LAGERAS, K. E. (2002) Visible intentions? Viewshed analysis of Bronze Age burial mounds in western Scania, Sweden. En Scarre, C. (ed.) Monuments and Landscape in Atlantic Europe. Perception and Society during the Neolithic and Early Bronze Age. London: Routledge, 2002, pp. 179-191

LILLIOS, K. (1999a) Lives of stones, lives of people: re-viewing the engraved plaques of Late Neolithic and Copper Age Iberia. European Journal of Archaeology, 7 (2), 1999, pp. 125-158

LILLIOS, K. (1999b) Objects of memory: the ethnography and archaeology of heirlooms. Journal of Archaeological Method and Theory, 6 (3), 1999, pp. 235-293

LILLIOS, K. (2003) Creating memory in Prehistory: the engraved slate plaques of southwest Iberia. En Van Dyke, R.; Alcock, S. (ed.) Archaeologies of Memory. Oxford: Blackwell, 2003, pp. 129-150

LORRIO ALVARADO, A. J.; MONTERO RUIZ, I. (2004) Reutilización de sepulcros colectivos en el Sureste de la Península Ibérica: la colección Siret. Trabajos de Prehistoria, 61 (1), 2004, pp. 99-116

MARTINÓN-TORRES, M. (2001) OS Monumentos Megalíticos Depois do Megalitismo. Arqueoloxía e Historia dos Megalitos Galegos a través das Fontes Escritas (s. VI-XIX). Pontevedra: Concello de Valga, 2001

MARTINÓN-TORRES, M.; RODRÍGUEZ CASAL, A. (2000) Aspectos historiográficos del megalitismo gallego: de la documentación medieval al siglo XIX. En Ramírez, P.; Cruz, D.; Enríquez, J.X:; Oliveira, J.: Sanches, M.J. (ed.) Actas do $3^{\circ}$ Congresso de Arqueologia Peninsular, vol. III, Neolitizaçao e Megalitismo da Península Ibérica. Porto: Adecap, pp. 303-320

MORLEY, I. (2007) Time, cycles and ritual behaviour. En Barrowclough, D. A.; Malone, C. (ed.) Cult in Context. Reconsidering Ritual in Archaeology. Oxford: Oxbow Books, 2007, pp. 205-210

OLIVEIRA, J.; SARANTOPOULOS, P.; BALESTEROS, C. (1997) Antas-Capelas e Capelas Junto a Antas no Territorio Portugués. Lisboa: Colibrí, 1997

O'SULLIVAN, M. (ed.) (2005) Tara. The Mound of the Hostages. Wicklow: University College Dublin, 2005

PARKER PEARSON, M.; RAMILISONINA (1998) Stonehenge for the ancestors: the stones pass on the message. Antiquity, 72 , 1998, pp. 308-326

PATTON, M. (1993) Statements in Stone: Monuments and Society in Neolithic Brittany. London: Routledge, 1993

ROBB, J. (2007) The Early Mediterranean village. Agency, Material Culture, and Social Change in Neolithic Italy. Cambridge: University Press, 2007

SHERRATT, A. (1990) The genesis of megaliths: monumentality, ethnicity and social complexity in Neolithic North-West Europe. World Archaeolog, 22 (2), 1990, pp. 147-167

SHERRATT, A. (1995) Instruments of conversion: the role of megaliths in the Mesolithic-Neolithic transition in North-West Europe. Oxford Journal of Archaeology, 14 (3), 1995, pp. 245-260

STOUT, G. (2002) Newgrange and the Bend of the Boyne. Cork: Cork University Press, 2002

THOMAS, J. (1993) The politics of vision and the archaeologies of landscape. En Bender, B. (ed.) Landscape, Politics and Perspectives. Oxford: Berg, 1993, pp.19-48

WHEATLEY, D. W. (1995) Cumulative viewshed analysis: A GISbased method for investigating intervisibility and its archaeological application. En Lock, G.; Stancic, Z. (ed.) Archaeology and Geographical Information Systems: A European Perspective. London: Taylor \& Francis, 1995, pp. 171-185

WHEATLEY, D. W. (1996) The use of GIS to understand regional variation in Neolithic Wessex. En Maschner, H. D. G. (ed.) (1996) New Methods, Old Problems. Geographic Information Systems in Modern Archaeological Research. Carbondale: Centre for Archaeological Investigations, 1996, pp. 75-103

WILLIAMS, H. M. R. (1998) The ancient monument in RomanoBritish ritual practices. En Forcey, C.; Hawthorne, J; Witcher, R. (ed.) TRAC97. Proceedings of the 7th Annual Theoretical Roman Archaeology Conference. Oxford: : Oxbow, 1998, pp. 71-86 